\title{
An advanced knowledge-based analysis of company vision statements
}

\author{
Alexander Kaiser \\ Vienna University of \\ Economics and Business \\ alexander.kaiser@wu.ac.at
}

\author{
Lisa-Maria Baumgartner \\ Vienna University of \\ Economics and Business \\ baumgartner@ai.wu.ac.at
}

\author{
Anna Grill \\ Vienna University of \\ Economics and Business \\ anna.grill@wu.ac.at
}

\author{
Sebastian Neumaier \\ St. Poelten University of \\ Applied Sciences \\ neumaier@fhstp.ac.at
}

\begin{abstract}
What distinguishes a good vision? A knowledge perspective on organizational visions can be helpful in order to identify which content vision statements should include. Knowledge enablers aim to respond to the question what organizations need to know for planning effectively and performing their activities well. Previous studies identified three knowledge enablers in organizational visions: knowledge about organizational identity $(O I)$, emerging potentiality $(E P)$ and mutual embeddedness (ME). In this paper, we empirically tested these findings through a qualitative content analysis of a large number of Forbes-2000 companies vision statements. As a result, we detected all three knowledge enablers in our sample. Moreover, we found that the rank of companies in the Forbes 2000 list correlates not only with the occurrence of knowledge enablers, but also with the frequency of knowledge about emerging potentiality. Consequently, companies have to be supported to generate especially this knowledge enabler. Our results can contribute to research on knowledge-based vision development and inspire an ongoing discussion in the KM community about future research priorities.
\end{abstract}

\section{Introduction}

While living in an environment that is characterized by high levels of volatility, uncertainty, complexity, and ambiguity (VUCA; [1]), it is crucial for an individual, for society and especially for organizations to have the capacities to get along with these dynamics of uncertainty. A sustainable and elaborated vision is an important factor to achieve a certain degree of stability and orientation in such turbulent and uncertain times. Uncertain insofar as the current phase is characterized by an expected restructuring of the global economic order in the wake of the Covid-19 pandemic, which "will irreversibly change how we view the world, do business, interact, and ultimately live our lives" [2]. As visions drive motivation [3, p.316], a vision's shared communication about an "ideal future state" [4, p.3] could potentially be a lighthouse to guide actions in organizations and could enable organizations to prepare for their future [5].

\subsection{Difference between vision and other concepts}

There are various definitions for the term "vision". O'Connell condensed a majority of these definitions by stating that a vision "is an idealized goal state, a set of blueprints for the future, an agenda, a map for members to follow, and an image of what needs to be achieved. It may include both long-term, future-oriented goals and emotional appeals embedded in a set of values; it is focused on change and depicts a future that is credible, realistic, attractive, inspiring, and better than the status quo" [6]. Importantly, visions are not the same as goals. Visions are rather general and per definition "never fully fulfilled in practice" [7, p.144], unlike goals. Further, a vision is not an objective as the latter needs to be attainable, observable, and measurable. Contrarily, a vision is more stable over time than plans, objectives and strategies [8]. According to Nonaka and Takeuchi [9. p.36] the differentiation between vision, mission and values can be best expressed by reducing them to the fundamental questions underlying them:

- Mission (Purpose): Why does your company exist?

- Vision (Dream): What kind of a future do you, and your fellow employees, want to create?

- Values (Beliefs): What values and beliefs do you and your colleagues hold dear?

There seems to be a common understanding in terms of how visions should look like. To give an example, Berson et al. list relative abstractness, an imagery basis, a broad scope and timelessness as characteristics of effective visions [7, p.144]. So are most vision statements today, between 11 and 22 words long, according to one empirical study [10]. Contrarily, Levin makes the case for using longer vision stories rather than vision statements, 
using "dynamic, vivid, imagery and colorful narrative descriptions of events, actions, and experiences"[11, p.96] to enable people to project the shared meaning of a vision in action and see themselves as part of this desirable future state. This last definition stresses the aspect of action, an emphasis that is shared by the definition of knowledge as "capacity to act" [12].

\subsection{Vision and knowledge}

Frequent themes in vision research concern issues of effective vision communication for visionary leadership [13, 14, 15, 16, 17]. Fewer papers specifically concern the process of vision development, or "vision content" [10, 17]. Before developing and implementing a vision in organizations, we have to identify what should be part of it so that the organization can take appropriate actions. However, hardly any publications address this issue. Therefore we ask: What makes a strong organizational vision? This is one of the question we are addressing in this paper. To do so, we take a knowledge perspective on visions. Consequently, our broader research interest in this field is to evaluate what types of knowledge (or knowledge enablers) should be considered in effective organizational visions. This question has already been investigated by Kragulj et al. [18] who identified three knowledge enablers: "knowledge about organizational identity", "emerging potentials" and "mutual embeddedness". One of the limitations of this exploratory work was the very small data set of visions that were analyzed. Our work wants to extend this earlier work and aims to verify whether the mentioned knowledge enablers can also be found in a larger sample. For this we have analyzed the visions of the Forbes 2000 companies. Consequently, our research question for this paper reads as follows:

Are the three previously identified knowledge enablers regarding knowledge about organizational identity, emerging potentiality and mutual embeddedness also identifiable in a very large data set such as the Forbes-2000 company visions?

In answering this question we will contribute in the broader research focus about the necessary knowledge types in effective organizational visions as well as to the body of literature about organizational vision development and open up avenues for future research.

In order to answer this research question we will use qualitative content analysis to evaluate the vision texts [19].

The paper is structured into four main sections. After this introduction, the second part highlights the empirical background of this research. We will discuss the formation of the data basis and the analysis process as well as the three knowledge enablers more in detail in that section. Subsequently, in section 3 and 4 the results of our analysis of the vision statements of Forbes-2000 companies are presented and the implications based on these results are discussed. In the end, the conclusion provides an outlook for further research.

\section{Empirical Background}

\subsection{Data basis}

The analysis and discussion in this paper is based on the Forbes' Global 2000 list of world's largest and most influential companies ${ }^{1}$ To compile this list, the Forbes magazine considers a number of measures, including sales, profits, assets and market value of the companies [20].

\section{\#1 ICBC}

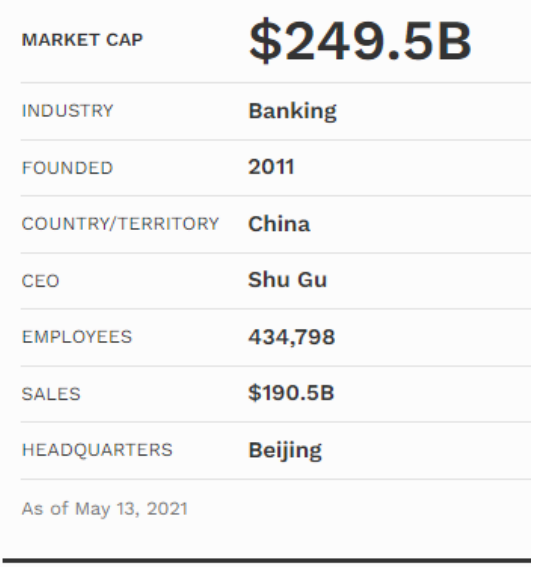

Figure 1. Forbes entry of the Industrial \& Commercial Bank of China.

The list, published online, includes general information about each company, such as the name, market value, industry, country, etc. An example of such a description is given in figure 1. However, the companies' mission and vision statements are not listed explicitly in the descriptions; also, we do not get any links to the companies' homepages where the statements are typically listed. To find the location and eventually the statements - we implemented the following approach:

1. Get Wikipedia entry of the listed companies: For each company we try to find the Wikipedia

\footnotetext{
${ }^{1}$ Note, that the list gets updated regularly; our results are based on an earlier version: https://www. forbes.com/lists/ global2000/
} 
entry via an automated Google search ${ }^{2}$ as search term we concatenate the name and the respective industry of the company (found in the Forbes list), inspect the first 10 results from Google, and select the highest ranked Wikipedia domain.

2. Get the homepage links from Wikipedia: The homogeneous structure of Wikipedia allows an automated extraction of the information in the article. In our approach we make use of the DBpedia project [21] which extracts the structured content from Wikipedia and makes it available on the Web. It allows to semantically query any relationships and properties of Wikipedia resources. We use the publicly available SPARQL endpoint of DBpedia 3 to get the homepage links of the listed companies based on the previously extracted Wikipedia entry.

3. Find statements on companies' homepages: To find the companies' statements on their homepages we again use automated Google searches: we search for the terms "vision" or "mission" but restrict our search results to the companies' domains $4^{4}$ However, we experienced that the vision statements are often not directly found on this page but on some sub-page (e.g. by following an internal link). Our heuristic to eventually get the text containing the vision statement is the following: we defined a set of keywords that we expect in the text; if a paragraph contains any of the keywords we extract this text, otherwise we follow all available internal links from this site, again looking for the defined keywords. The defined keywords are the following: ["mission", "vision", "intention", "guiding principle", "guiding principles", "future", "philosophy”, “our philosophy”, "strategy”, “core values", "values", "our values", "beliefs", "our beliefs", "mission statement", "vision statement", "outlook", "purpose", "our history", "history", "our mission", "our vision", "corporate social responsibility", "customer relationship", "plan”, "sustainability"].

An example of such an identified statement is given in figure 2. The result of this data collection phase was a folder with vision screenshots. To ensure

\footnotetext{
${ }^{2}$ The script for the automated search was written in the Python programming language; the Web scraping of the Google results was done using googlesearch-python (https://pypi.org/ project/googlesearch-python/1.

${ }^{3}$ For more information compare: https://dbpedia.org/ sparql

${ }^{4}$ Google allows to restrict the results to specific second or third-level domains using the "site:" attribute.
}

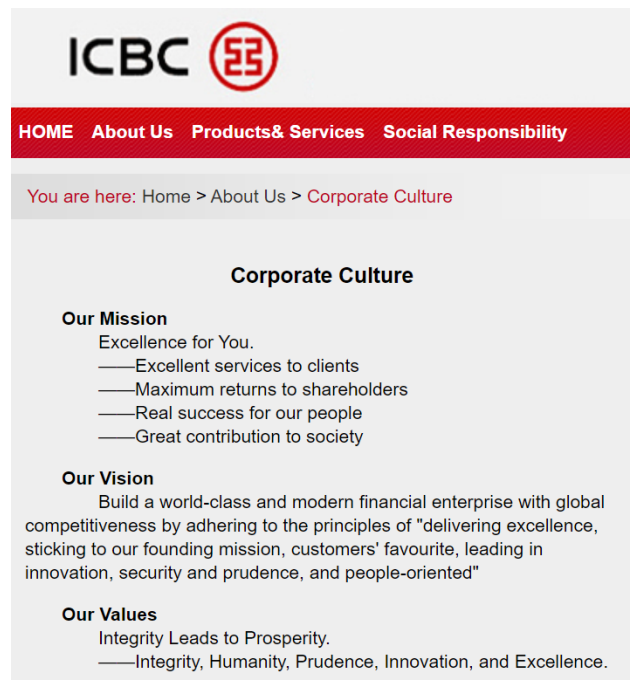

Figure 2. Mission and Vision Statements of the Industrial \& Commercial Bank of China.

that the homepages and the statements were extracted correctly, we manually reviewed all the results and corrected/completed the list if necessary.

\subsection{Description of manual review process}

The manual review process started with the sample of 2000 Forbes-companies, gathered in an IT-supported process, described above. Due to some technical errors only 1,846 screenshots were taken and saved in a separate folder. Of those images we excluded all items in the first manual review round when very obvious errors occured, e.g., blank images, non-English content, pop-ups with error messages, cropped texts, or product sites.

In a second manual review round, we evaluated, whether the remaining statements met the requirements for a real vision statement. To do this, we used the following definition of a vision statement according to the literature on visions that we presented in section 1.1. "a clear and purposeful image of a fulfilling and desirable future which can be described to others and which is possible to be realized in any - maybe extremely challenging - way, shape or form" [18].

The reason for choosing this definition is that it captures well the essential aspects of several other definitions [22, 23, 24, 10, 6], some of which also contain other features.

A large number of items did not fulfill the criteria in this step. Reasons for that were diverse. Sometimes, the heading even announced a "vision", but the text did not match our definition of a vision's characteristics. An example for this case is the vision of Alfa, in which 
they state among other points that their vision is to "encourage safe and sustainable operations. Contribute to the development of our communities." However, this statement does rather indicate a mission statement, especially because it is formulated in present tense and addresses tasks that are currently being made instead of an image of the future. During our selection process, we laid emphasis on the future-orientation, which is either easily recognizable by the tense used or by signal words such as "tomorrow" or "future". Another important factor in deciding whether a topic has been assigned as a vision is whether a clear image of the future has been given, which is possible to be realized.

Also, the crawler searched for several specific keywords as described in detail in section 2.1. This allowed us to find visions which were not labelled as such. For example, in some cases the text following the heading "mission" actually explained a vision rather than a mission. However, this also had as consequence that many screenshots taken only included statements on the mission, purpose, strategy, values of companies, statements of CEOs, or other texts, which, thus, had to be excluded from our further analysis.

In table 1 the exact steps of the selection process are listed including the concrete numbers of items. Consequently, our sample consists of exactly 400 visions, most of which were rather short in length and could thus be qualified as vision statements.

\begin{tabular}{|r|l|}
\hline $\begin{array}{r}\text { Nr. of } \\
\text { items } \\
\text { in sample }\end{array}$ & $\begin{array}{l}\text { Selection and } \\
\text { process description }\end{array}$ \\
\hline $\mathbf{2 , 0 0 0}$ & $\begin{array}{l}\text { Automated collection } \\
\text { of screenshots of vision } \\
\text { statements of Forbes- } \\
\text { Global-2000 (see 2.1.) }\end{array}$ \\
\hline-154 & No screenshot was taken \\
\hline-345 & Text not recognizable \\
\hline-143 & Error \\
\hline-54 & Not in English \\
\hline-83 & $\begin{array}{l}\text { Obviously observable } \\
\text { that this is not a vision }\end{array}$ \\
\hline $\mathbf{1 , 2 2 1}$ & $\begin{array}{l}\text { Nr. of items left for } \\
\text { content analysis }\end{array}$ \\
\hline-821 & $\begin{array}{l}\text { Not matching with } \\
\text { our vision definition }\end{array}$ \\
\hline $\mathbf{4 0 0}$ & $\begin{array}{l}\text { Visions left for } \\
\text { knowledge enabler } \\
\text { analysis }\end{array}$ \\
\hline
\end{tabular}

Table 1. Selection of sample

\subsection{Knowledge Enabler}

Now that the entire data sample was reduced to those statements that were in fact vision statements, we were able to begin the core part of the content analysis by assessing the degree to which the three knowledge enablers were included in each vision statement. Knowledge enablers ensure that an organization takes actions that correspond to what the organization should achieve, why this is relevant for the organization, and how the organization should act and behave. For this content analysis, we drew on the three knowledge enablers defined in [18], namely (1) knowledge about organizational identity, (2) knowledge about mutual embeddedness and (3) knowledge about emerging potentiality.

In the following, we provide some brief information about each of the enablers, based on the outcomes in [18].

Knowledge about organizational identity: This enabler refers to the self-conception of the organization, that is, who it is and who it wants to be. It covers the content domains "company's self-conception" and "industry leadership and innovation".

Knowledge about mutual embeddedness: This enabler refers to the context and the environment in which an organization is embedded, that is, anything that surrounds the organization. It covers the content domains "customers", "stakeholders", and "environment and society".

Knowledge about emerging potentiality: This enabler highlights that organizations need to grow and develop. Knowledge about emerging potentiality implies that organizations need to be able to perceive and interact with the environment such that they recognize opportunities for finding new manifestations of their identity.

In terms of the content analysis, these three knowledge enablers and the definitions and descriptions behind them constitute the coding scheme we use for our data analysis. Methodologically, however, our coding scheme also assesses whether the categories of the coding scheme are stable, whether new ones emerge, or whether there are aspects that are not considered by the scheme. The scheme is thus being strengthened and complemented - and at the same time helps to understand the primary data.

\section{Results of the content analysis}

Within this section we will present the results of our analysis. First, we illustrate the overall results of all 400 
visions analyzed in several dimensions and then deepen our analysis through including the three knowledge enablers in our investigation of specific patterns.

\subsection{Overall Results}

Geographically, the distributions of company headquarters in our sample as well as in the Forbes-2000 list are shown in table 2 . The sample represents the distribution of the Forbes-2000 companies quite accurately. Most visions in the sample are headquartered in Asia, followed by North American and European companies. South American and Oceanian companies are less present, whereas only very few company visions come from African companies.

\begin{tabular}{|l|c|c|}
\hline \multicolumn{3}{|c|}{ Regional distribution } \\
\hline Continent & Forbes 2000 & Our sample \\
\hline Africa & $1 \%$ & $1 \%$ \\
\hline Asia & $42 \%$ & $49 \%$ \\
\hline Europe & $23 \%$ & $21 \%$ \\
\hline North America & $31 \%$ & $25 \%$ \\
\hline Oceania & $2 \%$ & $2 \%$ \\
\hline South America & $2 \%$ & $3 \%$ \\
\hline
\end{tabular}

Table 2. Geographical distribution

Furthermore, we analyzed the length of the vision statements in terms of word count. In order to simplify the analysis, we introduced five different categories, in which we clustered the vision texts regarding their length. The result of this process is presented in table 3 . The longest item in our sample is Unilever's vision which is 495 words long. What is particularly noticeable is the dominance of rather brief vision statements as nearly two third of our sample visions contain below 41 words and are consequently quite concise. The average length of all visions in our analysis is 37 words.

\begin{tabular}{|c|c|}
\hline Length of vision text & Nr. of visions \\
\hline$<0-20$ words & 156 \\
\hline $21-40$ words & 138 \\
\hline $41-60$ words & 38 \\
\hline $61-80$ words & 26 \\
\hline$>80$ words & 42 \\
\hline
\end{tabular}

Table 3. Length of vision texts

This finding of short vision texts is in line with the recommended length of vision statements between 11 and 22 words of Kantabutra et al. [10]. They argue that shorter vision statements are preferable compared to longer ones due to their relative ease of communication and remembrance.
Regarding the content analysis of the vision texts in the sample we distinguished between two categories of abstract and specific visions. As "abstract" we classify any vision that could be easily replaceable as it does not hint on the company, industry or geographical location of its origin in the text. All other vision statements, that are more concrete regarding the context, are categorized as "specific". In total, we rated around two third of the vision statements as specific (63\% or 251 in absolute numbers) and about one third as abstract (37\%, 149 visions).

One example for an abstract vision is the following by LyondellBasell Industries:

We work every day to be the best operated and most valued company in our industry, today and tomorrow.

Contrarily, the vision of by Sydney Airport is an example for a specific vision statement:

Our vision is to deliver a world-class airport experience and foster the growth of Sydney Airport for the benefit of Sydney, NSW and Australia. Our airport is one of Australia's most important pieces of infrastructure.

\begin{tabular}{|r|c|c|}
\hline & specific & abstract \\
\hline Total sample size (400) & 251 & 149 \\
\hline Relative sample size $(s / a)$ & $63 \%$ & $37 \%$ \\
\hline
\end{tabular}

Table 4. Total and relative amount of abstract/specific vision statements

In the course of our analysis we have also counted, how often specific words appear in abstract and/or specific vision statements in our sample. Some of the words used most frequently are lead* (27 occurrences in abstract and 91 in specific vision texts), best (used 13 times in abstract and 32 times in specific visions), trust (was found 21 times in specific and 25 times in abstract visions), world-class (appears equally, 7 times in abstract and specific items) and innovat* (is present 21 times in abstract and 25 times in specific items of our sample).

\subsection{Knowledge enabler analysis in general}

Starting from the 400 selected visions, we analyzed if and to what degree the three knowledge enablers occurred.

In order to compare the degree to which the knowledge enablers were mentioned, we introduced a scale from 0 (non-existent) to 3 (definitely existent). The nuances in between were assigned when the knowledge enabler has not been clearly referred to, but somehow indirectly named.

The scale of four sub-categories per knowledge-enabler (0-3) emerged inductively based on a pre-test of categorizing vision examples. For the pre-test the three researchers that analysed the vision 
data, looked at some anchoring examples together to develop a shared subcategory scheme. These examples were collected in a shared memo to achieve intercoder reliability. This approach is in line with our method used, qualitative content analysis according to Schreier [19]. This method includes the possibility of reaching category frequencies by the inductive strategy of subsumption [25]. We assume that the use of a more nuanced scale would not have considerably changed the results validity, analogue to the finding that the use of 5-point or 7-point scales leads to comparable data that can easily be rescaled [26].

Table 5 provides an overview of the detailed results.

\begin{tabular}{|c|c|c|}
\hline emerging potentiality & degree & visions \\
\hline & 0 & 192 \\
\hline & 1 & 81 \\
\hline & 2 & 71 \\
\hline & 3 & 56 \\
\hline organizational identity & degree & visions \\
\hline & 0 & 40 \\
\hline & 1 & 71 \\
\hline & 2 & 135 \\
\hline & 3 & 154 \\
\hline mutual embeddedness & degree & visions \\
\hline & 0 & 127 \\
\hline & 1 & 80 \\
\hline & 2 & 100 \\
\hline & 3 & 93 \\
\hline
\end{tabular}

Table 5. Degree to which knowledge enablers occurred

Nearly all visions (360 of 400) included knowledge about organizational identity, knowledge about mutual embeddedness can be found in 273 visions, and about half (208/400) of the vision statements described knowledge about emerging potentiality. Altogether, only 149 visions included all three knowledge enablers to some degree.

On the basis of our classification scheme, a vision could be rated with up to 9 points, if all of the three knowledge enablers (knowledge about organizational identity, mutual embeddedness and emerging opportunities) are definitely existent in the respective vision text. One example for such a vision statement, scoring high on all three dimensions, is the following of the Asian car producer Mazda Motor:

We love cars and want people to enjoy fulfilling lives through cars. We envision cars existing sustainably with the earth and society, and we will continue to tackle challenges with creative ideas.

To give an overview regarding the overall scoring of the 400 sample visions, the absolute sum of points assigned in the three categories is shown in table 6 alongside the number of visions that reached the respective number of points.

\begin{tabular}{|c|c||c|c|}
\hline Score & Nr. of visions & Score & Nr. of visions \\
\hline 0 & 8 & 5 & 54 \\
\hline 1 & 19 & 6 & 65 \\
\hline 2 & 37 & 7 & 29 \\
\hline 3 & 106 & 8 & 19 \\
\hline 4 & 48 & 9 & 15 \\
\hline
\end{tabular}

Table 6. Points regarding the degree to which the three knowledge enablers occurred in total

\subsection{Regional distribution of visions and knowledge enablers}

In table 7 the regional distribution of the three knowledge enablers is presented. Due to a low number of vision texts from Africa the data of this continent is not really meaningful. Therefore, we have not included them in the following table. Except from this we found all three knowledge enablers in vision texts from all continents. Otherwise, we could not identify any clear pattern related to regional effects.

\subsection{Length of vision statements and the connection to knowledge enablers}

Visions, which include the knowledge enabler organizational identity, are especially concise with an average word count of only 39 words. Contrarily, vision statements that include knowledge about emerging potentiality have on average the longest word count with 50 words. While the occurrence of knowledge about organizational identity is almost unaffected by the length of the vision, one can clearly see that the longer the visions are, the more likely knowledge about emerging potentiality is included. An overview is illustrated in table 8

\subsection{Specific/abstract categories and their connection to knowledge enablers}

Finally, we examined the relationship between the abstract/specific categories and the occurrences of the knowledge enablers. While nearly half of the specific visions contain all three knowledge enablers, less than one-third of the abstract visions contain them completely. It is evident that all knowledge enablers are more present in the specific visions than in the abstract ones, with the highest difference between abstract and specific being evident at the knowledge about emerging potentiality. 


\begin{tabular}{|c|c|c|}
\hline \multicolumn{3}{|c|}{ Regional Distribution } \\
\hline $\begin{array}{l}\text { knowledge } \\
\text { enabler }\end{array}$ & continent & relative \\
\hline \multirow{5}{*}{$\begin{array}{l}\text { emerging } \\
\text { potentiality }\end{array}$} & Asia & $55 \%$ \\
\hline & Europe & $56 \%$ \\
\hline & North America & $42 \%$ \\
\hline & Oceania & $57 \%$ \\
\hline & South America & $64 \%$ \\
\hline \multirow{5}{*}{$\begin{array}{l}\text { organi- } \\
\text { zational } \\
\text { identity }\end{array}$} & Asia & $88 \%$ \\
\hline & Europe & $90 \%$ \\
\hline & North America & $92 \%$ \\
\hline & Oceania & $100 \%$ \\
\hline & South America & $100 \%$ \\
\hline \multirow{5}{*}{$\begin{array}{l}\text { mutual } \\
\text { embedded- } \\
\text { ness }\end{array}$} & Asia & $70 \%$ \\
\hline & Europe & $63 \%$ \\
\hline & North America & $71 \%$ \\
\hline & Oceania & $57 \%$ \\
\hline & South America & $64 \%$ \\
\hline
\end{tabular}

Table 7. Regional distribution per knowledge enabler

\begin{tabular}{|c|l|l|l|}
\hline \multirow{2}{*}{ Length of vision text } & \multicolumn{3}{|c|}{ Nr. of visions } \\
\cline { 2 - 4 } & EP & OI & ME \\
\hline $0-20$ words & $32 \%$ & $86 \%$ & $43 \%$ \\
\hline $21-40$ words & $54 \%$ & $92 \%$ & $78 \%$ \\
\hline $41-60$ words & $58 \%$ & $87 \%$ & $92 \%$ \\
\hline $61-80$ words & $88 \%$ & $96 \%$ & $88 \%$ \\
\hline$>80$ words & $90 \%$ & $98 \%$ & $98 \%$ \\
\hline average word count & 50 & 39 & 46 \\
\hline
\end{tabular}

Table 8. Length of vision texts depending on occurrence of knowledge enablers

Almost every specific vision contains knowledge about organizational identity. Table 9 gives an overview.

\begin{tabular}{|r|c|c|}
\hline & specific & abstract \\
\hline occurrence of EP in \% & $55 \%$ & $36 \%$ \\
\hline occurrence of OI in \% & $96 \%$ & $81 \%$ \\
\hline occurrence of ME in \% & $68 \%$ & $50 \%$ \\
\hline $\begin{array}{r}\text { occurrence of all three } \\
\text { knowledge enablers in \% }\end{array}$ & $43 \%$ & $27 \%$ \\
\hline
\end{tabular}

Table 9. Relative amount of abstract/specific vision statements in relation to all three knowledge enablers

\subsection{Coding Scheme}

As mentioned above regarding the content analysis, our coding scheme not only assesses whether the categories of the coding scheme are stable in the large data sample, but also whether new ones emerge, or whether there are aspects that are not considered by the scheme. The categories of our coding scheme were overall very stable. We did not detect any new categories that would be representative for a larger number of items. In nearly all visions - to be more precise in 392 out of 400 - we found at least one of the knowledge enablers, see table 6

\section{Implications of the content analysis}

Based on the detailed results of our content analysis presented in the previous section, we will now discuss the implications and findings in this section of the paper.

One of the most significant findings of our content analysis reveals that the three knowledge enablers in organizational visions identified in [18] based on a very small data sample are also found to be very stable in a large data sample of companies from very different areas. This actually already answers our research question of whether the three previous findings about organizational identity, emergent potentiality, and mutual embeddedness are identifiable even in a very large data set. Although all three knowledge enablers were well identified in the data sample of Forbes 2000 companies, beyond that the detailed analysis still offers very interesting insights.

\subsection{Three knowledge enablers}

Correlating the position in the ranking of the Forbes 2000 list with the occurrence of knowledge enablers in the visions of the companies, we can observe that in the top $10 \%$ of our analysis data sample, significantly more companies included all three knowledge enablers in their visions than for the total group (10\% vs. $3.8 \%)$.

In the table 10 we have illustrated some more detailed data which support this even more.

\begin{tabular}{|c|c|c|}
\hline knowledge enabler & TOP 40 & total sample \\
\hline EP & $22,5 \%$ & $14,0 \%$ \\
\hline OI & $45,0 \%$ & $38,5 \%$ \\
\hline ME & $32,5 \%$ & $23,3 \%$ \\
\hline EP \& OI & $15,0 \%$ & $6,8 \%$ \\
\hline EP \& ME & $12,5 \%$ & $4,8 \%$ \\
\hline OI \& ME & $17,5 \%$ & $11,8 \%$ \\
\hline all three & $10,0 \%$ & $3,8 \%$ \\
\hline
\end{tabular}

Table 10. Top 40 and all 400 companies compared regarding occurrence of knowledge enablers

Based on this data it can be argued that it has a positive effect on the success and sustainable development of a company if its vision includes all three knowledge enablers. 


\subsection{Knowledge about emerging potentialities}

Furthermore it can be clearly observed that the higher a company is in the Forbes 2000 rankings, the more often we can find the knowledge enabler about emerging potentiality. Table 11 shows some additional information about this insight - each of the ranking groups 1 to 10 contains 40 companies.

\begin{tabular}{|c|c|c|}
\hline Rank & $\begin{array}{l}\text { Nr. of visions } \\
\text { where EP } \\
\text { can be found }\end{array}$ & $\begin{array}{l}\text { Visions } \\
\text { where EP } \\
\text { can be found } \\
\text { (relative) }\end{array}$ \\
\hline $1 .-40$. & 25 & $63 \%$ \\
\hline $41 .-80$. & 25 & $63 \%$ \\
\hline $81 .-120$. & 24 & $60 \%$ \\
\hline $121 .-160$. & 19 & $48 \%$ \\
\hline $161 .-200$. & 19 & $48 \%$ \\
\hline $201 .-240$. & 21 & $53 \%$ \\
\hline $241 .-280$. & 19 & $48 \%$ \\
\hline $281 .-320$. & 21 & $53 \%$ \\
\hline $321 .-360$. & 17 & $43 \%$ \\
\hline $361 .-400$. & 18 & $45 \%$ \\
\hline
\end{tabular}

Table 11. EP related to ranking

If we illustrate the connection and the roles of the three knowledge enablers, it becomes clear that they form a kind of triangle to each other as shown in figure 3 The two knowledge enablers "organizational identity" and "mutual embeddedness" form the foundation and relate to the present and the past of a company by answering the question, who am I actually as a company and with whom do I interact (mutual embededdness). The knowledge enabler about "emerging potentiality", on the other hand, is much more related to the future of the company.

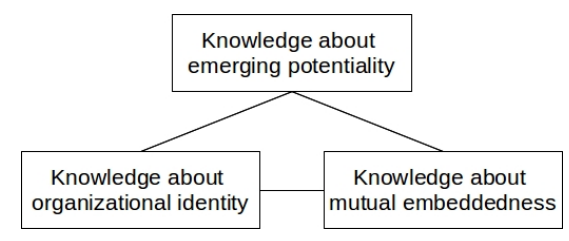

Figure 3. Knowledge enablers[18]

As mentioned above the enabler for knowledge about emerging potentiality is the most challenging and tricky one, as it implies that organizations need to be able to perceive and interact with the environment such that they recognize opportunities for finding new manifestations of their identity in the future.

Based on the data of our content analysis it can be assumed that the included knowledge about emerging opportunities in companies visions has also a positive impact. This is in line with the literature, that points out the importance of a "self-transcending" characteristic of a vision [27, 28, 29]. and that it is crucial "becoming sensitive for what wants to emerge (as a future potential) and how it is possible to shape reality (e.g. the organization) in such a way that it becomes beneficial both for the user and the organization."[30] Recently Nonaka and Takeuchi again point out that "the ultimate purpose of an organization is to realize the future it envisions, not just respond to changes in the environment in which it operates. Vision is visualizing "what kind of a future we want to create. Creating the future must extend beyond the company." [9, p.111]

Of course the question is how companies can best generate this knowledge about emerging potentialities. One approach is to expand the modes of organizational learning to include innovative types of learning, such as learning from the future as it emerges [31, 32]. There is very little work that specifically addresses this topic in the context of vision formation and vision development (e.g. [33, 34]). Since it is beyond the scope of this paper to discuss further possibilities, future work will have to focus on this topic.

\subsection{Vision length}

It is also interesting to see as shown in table 12 and illustrated in figure 4 that the length of the vision statements correlates with both the occurrence of all three knowledge enablers and the knowledge of emerging potentiality.

\begin{tabular}{|c|c|c|}
\hline $\begin{array}{c}\text { Length } \\
\text { of vision text }\end{array}$ & $\begin{array}{c}\text { Visions addressing all } \\
\text { 3 knowledge enablers }\end{array}$ & $\begin{array}{l}\text { Visions } \\
\text { with EP } \\
\text { (relative) }\end{array}$ \\
\hline $0-20$ words & $13 \%$ & $32 \%$ \\
\hline $21-40$ words & $36 \%$ & $54 \%$ \\
\hline $41-60$ words & $58 \%$ & $58 \%$ \\
\hline $61-80$ words & $77 \%$ & $88 \%$ \\
\hline$>80$ words & $86 \%$ & $90 \%$ \\
\hline
\end{tabular}

Table 12. Length of vision and emerging potentiality - table

Even though this is not very surprising and rather expected, it points to an issue that should be addressed in future work. How can a vision story be consolidated into a vision statement in a way that preserves all knowledge enablers? Solving this issue seems to be important because, on the one hand, it has been shown that the integration of the three knowledge enablers is important for the success of a company and, on the other hand, both literature and practice suggest that a vision statement has to be rather short [10]. 


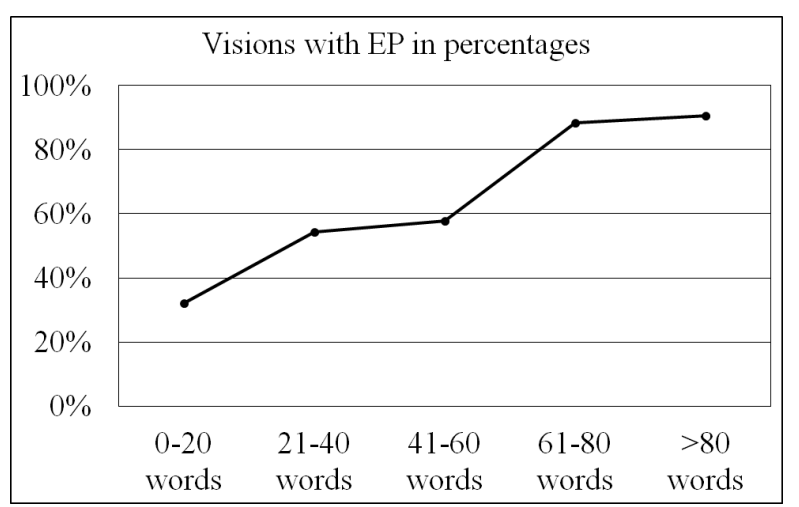

Figure 4. Length of vision and emerging potentiality - figure

\section{Conclusion}

In this paper, we conducted a qualitative content analysis of the vision statements of the companies listed in the Forbes 2000 list. We found that the three knowledge enablers of knowledge about emerging potentiality, knowledge about organizational identity and knowledge about mutual embeddedness in organizational visions, identified in [18], based on a small data sample are also stably evident in a large data sample of companies from very different content areas. Furthermore, it could be shown that the rank of the company in the Forbes 2000 list and the length of the visions correlate not only with the appearance of the three knowledge enablers, but especially with the knowledge about emerging potentiality

\subsection{Implications for theory and practice}

In this regard, this paper contributes both, to theory and practice. Theoretically, we contribute to research on knowledge-based vision development, inspire an ongoing discussion in the KM community about future research priorities and open up avenues for future research. With our work we close a little bit the gap between knowledge management and vision development. Furthermore, the results of our study have important implications for the field of knowledge-based vision development. As shown in [33], the process of developing an organizational vision can be seen as a knowledge-creating process in which new knowledge is created as well as existing knowledge is externalized and shared. The results of our work help to better shape this knowledge-creating process by structuring the types of knowledge.

Practically, we contribute the evidence that it has a positive impact on the success and sustainable development of a company if its vision includes all three knowledge enablers and, in particular, focuses on the knowledge about emerging potentiality. Therefore, companies must ensure that they not only plan their future based on past and present experiences, but also take the other way around and learn and develop from the future as it emerges, or as Nonaka and Takeuchi [35] call it in a recent paper "To survive, strategy must become more about shaping the future. To achieve this, companies must take an "inside-out" approach to their strategy." How companies can be efficiently supported in such kind of processes will be an important aspect of future work.

\subsection{Limitations and further research}

There are some limitations which should be addressed in future research. Although we conducted our content analysis on a pretty large dataset, a limitation of our research is that we only analyzed companies and that all of these companies are only from the Forbes list. If we consider visions of companies from other lists with a possibly different cultural focus or from not-for-profit organizations, we might get different results. Another limitation could be that due to a long research process, some vision statements have already been replaced online by updated texts. Based on these limitations and on some insights mentioned in this paper, our future research will cover at least the following areas:

- conducting an additional content analysis with non-profit organizations in order to evaluate whether the knowledge enablers can be identified there as well

- investigating approaches to support companies in generating knowledge about emerging potentialities and integrating it into their vision development processes

- developing methods to transform a vision story into a vision statement in a way that preserves all knowledge enablers

- development of a machine learning based approach, trained on the already extracted vision statements, to fully automate the finding of vision statements

\section{References}

[1] N. Bennett and G. J. Lemoine, "What a difference a word makes: Understanding threats to performance in a vuca world," Business Horizons, vol. 57, no. 3, pp. 311-317, 2014.

[2] N. Tovstiga and G. Tovstiga, "Covid-19: a knowledge and learning perspective," Knowledge Management Research \& Practice, pp. 1-6, 2020.

[3] P. Mirvis, B. Googins, and S. Kinnicutt, "Vision, mission, values," Organizational Dynamics, vol. 39, no. 4, p. 316, 2010. 
[4] J. L. Berg, "The role of personal purpose and personal goals in symbiotic visions," Frontiers in psychology, vol. 6 , p. 443, 2015 .

[5] D. Stam, R. G. Lord, D. v. Knippenberg, and B. Wisse, "An image of who we might become: Vision communication, possible selves, and vision pursuit," Organization Science, vol. 25, no. 4, pp. 1172-1194, 2014.

[6] D. O'Connell, K. Hickerson, and A. Pillutla, "Organizational visioning: An integrative review," Group \& Organization Management, vol. 36, no. 1, pp. 103-125, 2011.

[7] Y. Berson, N. Halevy, B. Shamir, and M. Erez, "Leading from different psychological distances: A construal-level perspective on vision communication, goal setting, and follower motivation," The Leadership Quarterly, vol. 26 , no. 2 , pp. $143-155,2015$.

[8] J. Kim and T. Oki, "Visioneering: an essential framework in sustainability science," Sustainability Science, vol. 6 , no. 2, pp. 247-251, 2011

[9] I. Nonaka and H. Takeuchi, The wise company: How companies create continuous innovation. Oxford University Press, 2019.

[10] S. Kantabutra and G. C. Avery, "The power of vision: statements that resonate," Journal of business strategy, 2010.

[11] I. M. Levin, "Vision revisited: Telling the story of the future," The Journal of Applied Behavioral Science, vol. 36, no. 1, pp. 91-107, 2000.

[12] N. Stehr and R. Grundmann, "How does knowledge relate to political action?," Innovation: The European Journal of Social Science Research, vol. 25, no. 1, pp. 29-44, 2012.

[13] A. M. Carton and B. J. Lucas, "How can leaders overcome the blurry vision bias? identifying an antidote to the paradox of vision communication," Academy of Management Journal, vol. 61, no. 6, pp. 2106-2129, 2018

[14] D. Van Knippenberg and D. Stam, "Visionary leadership," The Oxford handbook of leadership and organizations, vol. 241, p. 259, 2014.

[15] J. J. Sosik and S. L. Dinger, "Relationships between leadership style and vision content: The moderating role of need for social approval, self-monitoring, and need for social power," The Leadership Quarterly, vol. 18, no. 2 pp. 134-153, 2007.

[16] R. Awamleh and W. L. Gardner, "Perceptions of leader charisma and effectiveness: The effects of vision content delivery, and organizational performance," The leadership quarterly, vol. 10, no. 3, pp. 345-373, 1999.

[17] J. R. Baum, E. A. Locke, and S. A. Kirkpatrick, "A longitudinal study of the relation of vision and vision communication to venture growth in entrepreneurial firms.," Journal of applied psychology, vol. 83, no. 1, p. 43,1998

[18] F. Kragulj, A. Kaiser, and T. Grisold, "Identifying knowledge enablers in organizational visions: A synthesis of theory and practice," in Proceedings of the 51st Hawaii International Conference on System Sciences, 2018.

[19] M. Schreier, Qualitative content analysis in practice. Sage publications, 2012.

[20] Forbes, "Forbes global 2000 [online]," Available: https://www.forbes.com/sites/andreamurphy/2018/06/06/ 2018-global-2000-methodology-how-we-crunch-thenumbers, [Accessed: 06- Jun- 2018].
[21] S. Auer, C. Bizer, G. Kobilarov, J. Lehmann, R. Cyganiak, and Z. G. Ives, "Dbpedia: A nucleus for a web of open data," in The Semantic Web, 6th International Semantic Web Conference, 2nd Asian Semantic Web Conference, ISWC $2007+$ ASWC 2007, Busan, Korea, November 11-15, 2007, vol. 4825 of Lecture Notes in Computer Science, pp. 722-735, Springer, 2007.

[22] J. R. Lucas, "Anatomy of a vision statement," Management Review, vol. 87, no. 2, p. 22, 1998.

[23] R. J. House and B. Shamir, "Toward the integration of transformational, charismatic, and visionary theories.," 1993.

[24] J. V. Quigley, "Vision: How leaders develop it, share it, and sustain it," Business Horizons, vol. 37, no. 5, pp. 37-42, 1994.

[25] P. Mayring, "Qualitative content analysis: Demarcation, varieties, developments," in Forum Qualitative Sozialforschung/Forum: Qualitative Social Research, vol. $20,2019$.

[26] J. Dawes, "Do data characteristics change according to the number of scale points used? an experiment using 5-point, 7-point and 10-point scales," International journal of market research, vol. 50, no. 1, pp. 61-104, 2008.

[27] A. Kaiser and B. Fordinal, "Creating a ba for generating self-transcending knowledge," Journal of Knowledge Management, vol. 14, no. 6, pp. 928-942, 2010.

[28] C. O. Scharmer, "Self-transcending knowledge: sensing and organizing around emerging opportunities," Journal of knowledge Management, 2001.

[29] P. M. Senge, The fifth discipline: The art and practice of the learning organization. Currency, 2006.

[30] M. F. Peschl, "Unlearning towards an uncertain future: on the back end of future-driven unlearning," The Learning Organization, 2019.

[31] M. F. Peschl and T. Fundneider, "Future-oriented innovation: How affordances and potentials can teach us how to learn from the future as it emerges," in The Future Information Society: Social and Technological Problems, pp. 223-240, World Scientific, 2017.

[32] C. O. Scharmer, Theory U: Learning from the future as it emerges. Berrett-Koehler Publishers, 2009.

[33] A. Kaiser, B. Feldhusen, and B. Fordinal, "Vision development as a knowledge creating process," in 2013 46th Hawaii International Conference on System Sciences, pp. 3593-3602, IEEE, 2013

[34] A. Kaiser, F. Fahrenbach, and H. Martinez, "Creating shared visions in organizations-taking an organizational learning and knowledge management perspective," in Proceedings of the 54th Hawaii International Conference on System Sciences, p. 5186, 2021.

[35] I. Nonaka and H. Takeuchi, "Humanizing strategy," Long Range Planning, p. 102070, 2021. 